\title{
Siderophore uptake and use by the yeast Saccharomyces cerevisiae
}

\author{
Emmanuel Lesuisse, ${ }^{1}$ Pierre-Louis Blaiseau, ${ }^{1}$ Andrew Dancis ${ }^{2}$ \\ and Jean-Michel Camadro ${ }^{1}$
}

Author for correspondence: Emmanuel Lesuisse. Tel: +331442763 56. Fax: +331442757 16. e-mail: lesuisse@ijm.jussieu.fr

\footnotetext{
1 Laboratoire d'Ingénierie des Protéines et Contrôle Métabolique, Institut Jacques Monod, Tour 43, Université Paris 7/Paris 6, 2 place Jussieu, 75251 Paris cedex 05, France

2 University of Pennsylvania, Department of Medicine, Division of Hematology/ Oncology, BRBII Room 731, 431 Curie Blvd, Philadelphia, PA 19104, USA
}

\begin{abstract}
The non-reductive uptake of several siderophores (ferrioxamine B, ferrichrome, triacetylfusarinine $C$ and ferricrocin) by various strains of Saccharomyces cerevisiae was studied. Several aspects of siderophore transport were examined, including specificity of transport, regulation of transport and intracellular localization of the ferri-siderophores. Ferrioxamine B was taken up preferentially via the products of the SIT1 gene and triacetylfusarinine C by the TAF1 gene product, but the specificity was not absolute. Ferrichrome and ferricrocin uptake was not dependent on a single major facilitator superfamily (MFS) gene product. The apparent specificity of transport was strongly dependent on the genetic background of the cells. Non-reductive uptake of siderophores was induced under more stringent conditions (of iron deprivation) than was the reductive uptake of ferric citrate. Regulation of transport depended on the transcriptional factors Aft1 and Tup1/Ssn6. Cells disrupted for the TUP1 or SSN6 genes were constitutively derepressed for the uptake of ferrichrome, ferricrocin or ferrioxamine B, but not for the uptake of triacetylfusarinine C. Cells bearing the AFT1up mutation accumulated large amounts of ferric siderophores. Intracellular decomplexation of the siderophores occurred when transcription of the AFT1up gene was repressed. Ferrioxamine $B$ and ferrichrome seemed to accumulate in an endosomal compartment, as shown by biochemical studies and by confocal microscopy study of cells loaded with a fluorescent derivative of ferrichrome. Endocytosis was, however, not involved in the non-reductive uptake of siderophores.
\end{abstract}

Keywords: iron, siderophore, yeast, Saccharomyces cerevisiae

\section{INTRODUCTION}

The yeast Saccharomyces cerevisiae can use two different high-affinity mechanisms (reductive and nonreductive) to take up iron from the extracellular medium. The reductive mechanism (Lesuisse et al., 1987; Dancis et al., 1990) involves the labilization of extracellular ferric chelates by reduction at the surface of the cells via the inducible plasma membrane reductases Fre1p and Fre2p (Dancis et al., 1992; Georgatsou \& Alexandraki, 1994). A permease-oxidase complex (Ftr1p and Fet3p) is then involved in translocating iron through the plasma membrane (Askwith et al., 1994; Stearman et al., 1996). The non-reductive

\footnotetext{
Abbreviations: BPS, bathophenanthrolinedisulfonate; FC, ferricrocin ; $\mathrm{FCH}$, ferrichrome; FOB, ferrioxamine $\mathrm{B}$, mesylate form (Desferal); MFS, major facilitator superfamily; TAF, triacetylfusarinine $C$.
}

mechanism requires that a ferric complex enters the cells prior to any reduction step. In 1989, we described a nonreductive mechanism for ferrioxamine $\mathrm{B}$ (FOB) uptake by $S$. cerevisiae (Lesuisse \& Labbe, 1989). This siderophore can enter cells via an FOB receptor present at the cell surface. We showed that the siderophore transport system of $S$. cerevisiae is specific, saturable, energydependent and has a high affinity for FOB (Lesuisse \& Labbe, 1989). We called this an 'opportunistic strategy of iron uptake' because $S$. cerevisiae can use siderophores excreted by other micro-organisms although it does not produce any itself. The presence in a fungus of two different uptake systems, one reductive and another non-reductive, was first demonstrated by Ecker \& Emery (1983) for Ustilago sphaerogena.

The existence of two mechanisms for iron uptake makes the specific study of non-reductive uptake somewhat complicated. Uptake kinetics do not fit well with simple 
Michaelis-Menten representations (Lesuisse \& Labbe, 1989). Reduction of siderophores at the cell surface is a low-affinity and low-specificity mechanism. At low extracellular concentrations (around $1 \mu \mathrm{M}$ ), uptake of the siderophore is essentially non-reductive. When the siderophore concentration is raised, the reductive mechanism becomes quantitatively more important as the non-reductive, high-affinity system approaches saturation (Lesuisse \& Labbe, 1989). Genetic studies are also not simple: a mutation that affects some step of nonreductive iron assimilation in $S$. cerevisiae will be difficult to detect because iron can still enter the cells by the reductive mechanism. Emery (1986) used gallium analogues of siderophores, which cannot be reduced, to distinguish between reductive and non-reductive uptake of siderophores by U. sphaerogena. We used mutants of $S$. cerevisiae in which the FET3 and FET4 genes, encoding components of the high-affinity and low-affinity reductive uptake systems, respectively (Askwith et al., 1994; Dix et al., 1994), had been deleted. Such mutants are unable to grow on minimum medium (containing about $1 \mu \mathrm{M}$ iron) unless a siderophore (or large amounts of a ferric salt) is added to the growth medium. This property allowed us to select mutants unable to take up FOB, and to identify a gene, SIT1 (Siderophore Iron Transport), whose product is probably responsible for the translocation of FOB through the plasmalemma (Lesuisse et al., 1998). Sit1p belongs to the major facilitator superfamily (MFS) and has several homologues that may be expected to participate in the transport of other siderophores. This was recently demonstrated in three short studies (Heymann et al., 1999, 2000a, b) in which the authors attributed the product of the YHL047c ORF to triacetylfusarinine $\mathrm{C}(\mathrm{TAF})$ transport, the product of the YHL040c ORF to the transport of a specific class of ferrichromes (FCHs), possessing anhydromevalonyl residues linked to $N(\delta)$-ornithine, and the product of the YOL158c ORF to the transport of enterobactin. They postulated that the product of any single gene of the SIT family was responsible for recognizing and transporting a single siderophore. This is not consistent with our own observations (present work) or with other recently published results (Yun et al., 2000b). The present report re-examines some aspects of siderophore transport by $S$. cerevisiae, including the specificity of transport, energy requirements, the regulation of transport and the intracellular use of iron. To respect priority of names and to avoid unnecessary confusion, the following nomenclature is used throughout the paper: YEL065 $\mathrm{w}$ is referred to as SIT1 (Lesuisse et al., 1998), YHL047c as TAF1, YHL040c as ARN1 and YOL158c as ENB1 (Heymann et al., 1999, 2000a, b).

\section{METHODS}

Strains, media and iron compounds. The various strains of $S$. cerevisiae used in this study are described in Table 1 . Unless otherwise stated, cells were grown at $30^{\circ} \mathrm{C}$ (in $50 \mathrm{ml}$ Falcon tubes in a gyroshaker) in minimal YNB-glucose (without copper and iron) medium (Bio101) plus the required amino acids, $1 \mu \mathrm{M}$ copper sulphate and various iron sources (siderophores or ferric citrate). For iron-deficient cultures, $100 \mu \mathrm{M}$ BPS (bathophenanthrolinedisulfonate) was added to YNBglucose medium without copper and iron. Desferri-compounds were obtained as described by Wiebe \& Winkelmann (1975). When required, they were labelled with ${ }^{55} \mathrm{Fe}[50$ $\left.\mathrm{mCi} \mathrm{mg}^{-1}\left(1.85 \mathrm{GBq} \mathrm{mg}^{-1}\right)\right]$. Throughout this work, the name '(des)ferrioxamine B' refers to the commercially available mesylate derivative, Desferal (Novartis). The fluorescent derivative of FCH used was the glycine-based analogue B9 described by Berner et al. (1991).

Iron uptake assays. Iron uptake was measured in microtitration plates. Cells were grown overnight at $30^{\circ} \mathrm{C}$ in various media (as specified above) to stationary phase. In the morning, cells were diluted 10 -fold in the same medium and cultured for $6 \mathrm{~h}$ at $30^{\circ} \mathrm{C}$. Cells were then washed three times with distilled water and suspended in $50 \mathrm{mM}$ citrate (trisodium) buffer ( $\mathrm{pH} 6.5$ ) containing $5 \%$ glucose to give an $\mathrm{OD}_{600}$ of 3 . The cell suspension was distributed into the wells of a micro-titration plate $(50 \mu \mathrm{l}$ cells per well $)$ at $0{ }^{\circ} \mathrm{C}$. Iron was added (as a ${ }^{55} \mathrm{Fe}$ chelate) to give a final concentration of $1-5 \mu \mathrm{M}$ and the plate was incubated for $15-60 \mathrm{~min}$ at $30^{\circ} \mathrm{C}$. The cells were collected with a cell harvester (Brandel) and washed on a filter.

Cell fractionation. Cell fractions were purified (Raguzzi et al., 1988) after protoplast lysis (moderate osmotic shock) by centrifugation on a discontinuous Ficoll gradient.

Other. Low-temperature spectra $\left(-191^{\circ} \mathrm{C}\right)$ of whole cells were prepared as described by Lesuisse \& Labbe (1989). The optical path length was $1 \mathrm{~mm}$ and the reference was a single sheet of wet filter paper. Spectra were corrected for baseline shift. SDS-PAGE and subsequent transfer to nitrocellulose were done using standard procedures. The proteins on nitrocellulose were probed with monoclonal antibodies or with an antiserum specific for Hem $15 \mathrm{p}$ that was purified in our laboratory (Camadro \& Labbe, 1988). Primary antibodies were detected with a horseradish-peroxidase-conjugated antimouse IgG and ECL chemiluminescence (Amersham). Fluorescence confocal microscopy was performed as described by Ardon et al. (1998). Cells bearing the AFT1 $1^{\text {up }}$ mutation were grown overnight on a minimum medium containing $10 \mu \mathrm{M}$ of fluorescent $\mathrm{FCH}$ analogue and then examined for intracellular fluorescence. New mutants affected in siderophore transport were generated by insertion mutagenesis $(\operatorname{Tn} 3)$ as described by Burns et al. (1994). Conditional expression of AFT1 $1^{\text {up }}$ was done by cloning the $A F T 1^{\text {up }}$ ORF into the centromeric plasmid pRS316-Gal.

\section{RESULTS}

\section{The specificity of Sit1 and homologues for various siderophores is not absolute}

We previously showed (Lesuisse et al., 1998) that FOB and ferricrocin (FC) are taken up by $S$. cerevisiae via an active transport system, and that Sit $1 \mathrm{p}$ is responsible for the uptake of FOB. It was then predictable that gene products homologous to Sit $1 \mathrm{p}$ should be involved in the uptake of other siderophores. We subsequently identified $\mathrm{FCH}$ and TAF as siderophores transported by an active, energy-dependent mechanism by $S$. cerevisiae. This has also been reported recently by others (Yun et al., 2000b; Heymann et al., 1999). We measured the rate of uptake of FOB, FC, FCH, TAF and ferric citrate by a 
Table 1. Description of S. cerevisiae strains used

\begin{tabular}{|c|c|}
\hline Strain name & Genotype \\
\hline DEY1455 & MAT $\alpha$ ade 2 can1 his3 leu2 trp1 ura3 gal (wild-type) \\
\hline DEY1433 & MAT $\alpha$ ade 2 his 3 leu 2 trp 1 ura 3 fet $3::$ HIS 3 fet $4::$ LEU2 \\
\hline DDY4 & MAT a ade6 can1 his3 leu 2 trp1 ura3 fet3-2:: HIS3 fet4-1:: LEU2 \\
\hline DEY1455 $\Delta$ sit1 & MAT $\alpha$ ade 2 can1 his3 leu2 trp1 ura3 gal sit $1:$ :KanMX4 \\
\hline DEY1433 $\Delta$ sit1 & MAT $\alpha$ ade 2 his 3 leu 2 trp1 ura3 fet $3:$ :HIS3 fet $4:$ :LEU2 sit $1::$ KanMX4 \\
\hline CM3260 & MAT $\alpha$ trp1 leu2 gcn 4 his 3 ura3 (wild-type) \\
\hline CM3260ssit1 & MAT $\alpha$ trp1 leu2 gon4 his3 ura3 sit1::KanMX4 \\
\hline $\mathrm{M} 2 \mathrm{p}$ & MAT $\alpha$ trp1 leu2 gcn4 his3 ura3 AFT1up \\
\hline 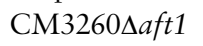 & MAT a trp1 leu2 gen4 his3 ura3 aft1:: TRP1 \\
\hline BY4742 & MAT $\alpha$ lys2 leu2 his 3 ura3 (wild-type) \\
\hline 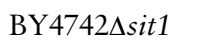 & MAT $\alpha$ lys 2 leu 2 his 3 ura3 sit $1:$ KanMX4 \\
\hline BY $4742 \Delta t a f 1$ & MAT $\alpha$ lys2 leu2 his3 ura3 taf1:: KanMX4 \\
\hline BY4742هarn1 & MAT $\alpha$ lys 2 leu2 his 3 ura 3 arn1:: KanMX4 \\
\hline 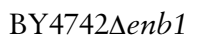 & MAT $\alpha$ lys 2 leu2 his3 ura3 enb1::KanMX4 \\
\hline NY13 & MATa act1 ura3 gal2 \\
\hline FY105 & MATa leu2 his3 ura3 (wild-type) \\
\hline BSHFT5 & MAT $\alpha$ leu 2 his 3 ura3 tup1 ::HIS3 \\
\hline PHF105 & MAT $\alpha$ leu 2 his 3 ura 3 ssn $6:: H I S 3$ \\
\hline
\end{tabular}

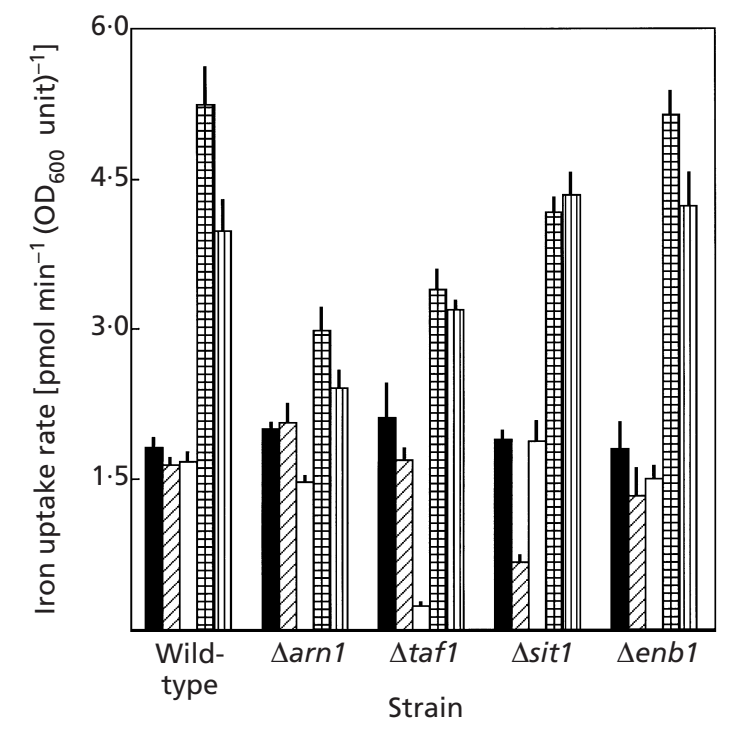

Fig. 1. Iron uptake by various strains of $S$. cerevisiae from different iron sources. Strains of the BY4742 background disrupted for the ARN1, TAF1, SIT1 or ENB1 ORFs were first cultured overnight in iron-deficient medium (without iron, but with $1 \mu \mathrm{M}$ copper). Cultures were then diluted 10 -fold in the same medium $+100 \mu \mathrm{M}$ BPS and cultured for $6 \mathrm{~h}$ before iron uptake was measured as described in Methods. Iron sources tested (each $1 \mu \mathrm{M}$ ) were: ferric citrate $(\boldsymbol{\square})$, FOB $(\square)$, TAF $(\square)$, FCH (囲), and FC (四). Values are means \pm SE from 15 independent experiments.

wild-type strain and isogenic mutants disrupted for either the SIT1 gene, the TAF1 gene, the ARN1 gene or the ENB1 gene to evaluate the contribution of Sit1p and homologues to the transport of these various siderophores (Fig. 1). These data indicate that TAF transport mainly depends on TAF1, as recently shown by Heymann et al. (1999). FCH transport was affected in strains in which the ARN1, TAF1 or SIT1 genes were disrupted (Fig. 1). This confirms the recent results of Yun et al. (2000b) showing that FCH uptake does not depend on a single MFS gene. Our data also indicate that the same is true for the FCH-type siderophore FC. Transport of that siderophore was affected in strains whose ARN1 or TAF1 genes were disrupted (Fig. 1). Curiously, disruption of ARN1 seemed to facilitate the transport of FOB (Fig. 1). Members of the Sit family are thus not completely specific for a single siderophore. SIT1 and TAF1 seem to encode the most specific transporters, for FOB and TAF, respectively. The relative non-specificity of the transporters was also indicated by the following observation. Constitutive overexpression of the SIT1 ORF in various strains led to an increase in the rate of uptake of FOB, but also of FC and $\mathrm{FCH}$, and to a lesser extent of TAF (Table 2).

Analysis of new mutants also indicated that each Sitp member is not completely specific for a single siderophore. Cells lacking the YFH1 gene are sensitive to iron (Babcock et al., 1997), especially when it is presented as FOB, FC or FCH (see below). We used this property to select new mutants able to grow on plates enriched with $10 \mu \mathrm{M} \mathrm{FCH}$. One of these mutants could not take up FOB, FCH or FC. The transport of these three siderophores by the mutant cells was restored when they were transformed with SIT1 on a multicopy plasmid (data not shown). Other mutants obtained in this way are being analysed. We previously showed that FC uptake is completely unaffected when the SIT1 gene is disrupted in the strain DEY1433 (Lesuisse et al., 1998). We disrupted the same gene in strains of various genetic backgrounds and observed that the effect of SIT1 disruption on siderophore transport differed greatly 
Table 2. Iron uptake from different sources by various strains of S. cerevisiae

Strains of the BY4742 background disrupted for ARN1, TAF1 or SIT1 ORFs were transformed with a plasmid bearing the SIT1 ORF under a strong constitutive promoter (pVT100U-SIT1). Transformed and untransformed cells were first cultured overnight in iron-deficient medium (without iron but with $1 \mu \mathrm{M}$ copper), diluted 10-fold in the same medium $+100 \mu \mathrm{M}$ BPS and cultured for $6 \mathrm{~h}$. Iron uptake from ferric citrate, FOB, TAF, FC or FCH (each $2 \mu \mathrm{M}$ ) was then measured as described in Methods. Values are means $\pm \mathrm{sE}$ from three independent experiments.

\begin{tabular}{|c|c|c|c|c|c|}
\hline \multirow[t]{2}{*}{ Strain } & \multicolumn{5}{|c|}{ 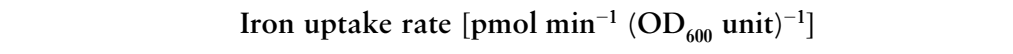 } \\
\hline & $\mathrm{Fe}(\mathrm{III})$ citrate & FOB & TAF & FC & $\mathrm{FCH}$ \\
\hline Wild-type & $1 \cdot 2 \pm 0 \cdot 30$ & $1 \cdot 3 \pm 0 \cdot 20$ & $0 \cdot 9 \pm 0 \cdot 05$ & $2 \cdot 9 \pm 0 \cdot 40$ & $4 \cdot 2 \pm 0 \cdot 30$ \\
\hline$\Delta a r n 1$ & $1 \cdot 1 \pm 0 \cdot 20$ & $1 \cdot 5 \pm 0 \cdot 15$ & $0 \cdot 8 \pm 0 \cdot 03$ & $2 \cdot 1 \pm 0 \cdot 30$ & $2 \cdot 9 \pm 0 \cdot 30$ \\
\hline$\Delta t a f 1$ & $1 \cdot 3 \pm 0 \cdot 20$ & $1 \cdot 7 \pm 0 \cdot 10$ & $0 \cdot 1 \pm 0 \cdot 02$ & $3 \cdot 1 \pm 0 \cdot 35$ & $3 \cdot 6 \pm 0 \cdot 20$ \\
\hline$\Delta$ sit1 & $0 \cdot 9 \pm 0 \cdot 15$ & $0 \cdot 3 \pm 0 \cdot 04$ & $1 \cdot 2 \pm 0 \cdot 01$ & $2 \cdot 8 \pm 0 \cdot 20$ & $2 \cdot 7 \pm 0 \cdot 40$ \\
\hline Aarn1-SIT1 & $1 \cdot 2 \pm 0 \cdot 10$ & $4 \cdot 0 \pm 0 \cdot 30$ & $1 \cdot 8 \pm 0 \cdot 15$ & $4 \cdot 1 \pm 0 \cdot 30$ & $5 \cdot 2 \pm 0 \cdot 60$ \\
\hline$\Delta t a f 1-S I T 1$ & $1 \cdot 0 \pm 0 \cdot 20$ & $5 \cdot 8 \pm 0 \cdot 40$ & $0 \cdot 3 \pm 0 \cdot 01$ & $4 \cdot 6 \pm 0 \cdot 50$ & $5 \cdot 7 \pm 0 \cdot 50$ \\
\hline$\Delta s i t 1-S I T 1$ & $1 \cdot 3 \pm 0 \cdot 15$ & $5 \cdot 2 \pm 0 \cdot 30$ & $1 \cdot 4 \pm 0 \cdot 10$ & $4 \cdot 5 \pm 0 \cdot 40$ & $5 \cdot 2 \pm 0 \cdot 30$ \\
\hline
\end{tabular}

\section{Table 3. Iron uptake from different sources by various strains of S. cerevisiae}

Strains of different genetic backgrounds were tested for iron uptake before and after disruption of the SIT1 gene. Cells were cultured overnight in iron-deficient medium (without iron but with $1 \mu \mathrm{M}$ copper), diluted 10-fold in the same medium $+100 \mu \mathrm{M}$ BPS and cultured for $6 \mathrm{~h}$. Iron uptake from ferric citrate, FOB, TAF, FC or FCH (each $2 \mu \mathrm{M}$ ) was then measured as described in Methods. Values are means \pm sE from three independent experiments.

\begin{tabular}{|c|c|c|c|c|c|}
\hline \multirow[t]{2}{*}{ Strain } & \multicolumn{5}{|c|}{ Iron uptake rate $\left[\mathrm{pmol} \mathrm{min}^{-1}\left(\mathrm{OD}_{600} \text { unit }\right)^{-1}\right]$} \\
\hline & $\mathrm{Fe}(\mathrm{III})$ citrate & FOB & TAF & FC & $\mathrm{FCH}$ \\
\hline CM3260 & $0 \cdot 9 \pm 0 \cdot 07$ & $1 \cdot 5 \pm 0 \cdot 16$ & $0 \cdot 4 \pm 0 \cdot 05$ & $3 \cdot 5 \pm 0 \cdot 40$ & $4 \cdot 3 \pm 0 \cdot 35$ \\
\hline CM3260_sit1 & $1 \cdot 2 \pm 0 \cdot 10$ & $0 \cdot 3 \pm 0 \cdot 01$ & $0 \cdot 3 \pm 0 \cdot 02$ & $1 \cdot 3 \pm 0 \cdot 10$ & $1 \cdot 8 \pm 0 \cdot 20$ \\
\hline DEY1433 & $0 \cdot 07 \pm 0 \cdot 01$ & $2 \cdot 4 \pm 0 \cdot 15$ & $0 \cdot 7 \pm 0.09$ & $5 \cdot 5 \pm 0 \cdot 50$ & $5 \cdot 9 \pm 0.65$ \\
\hline DEY1433 ssit1 & $0 \cdot 05 \pm 0 \cdot 01$ & $0 \cdot 2 \pm 0 \cdot 03$ & $0 \cdot 6 \pm 0 \cdot 05$ & $5 \cdot 9 \pm 0 \cdot 50$ & $5 \cdot 6 \pm 0 \cdot 60$ \\
\hline BY 4742 & $1 \cdot 3 \pm 0 \cdot 07$ & $1 \cdot 4 \pm 0 \cdot 10$ & $1 \cdot 0 \pm 0 \cdot 16$ & $3 \cdot 2 \pm 0 \cdot 40$ & $4 \cdot 0 \pm 0 \cdot 60$ \\
\hline 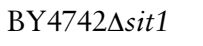 & $1 \cdot 2 \pm 0 \cdot 15$ & $0 \cdot 3 \pm 0 \cdot 02$ & $1 \cdot 3 \pm 0 \cdot 11$ & $3 \cdot 1 \pm 0 \cdot 35$ & $2 \cdot 5 \pm 0 \cdot 20$ \\
\hline
\end{tabular}

from one strain to another (Table 3). Disruption of SIT1 led to a specific defect in FOB uptake in cells of the DEY1433 background, but it led to a decrease in FOB, FC and FCH uptake in cells of the CM3260 background (Table 3). SIT1 disruption affected FOB and FC uptake by cells of the BY4742 background, but not that of FCH (Fig. 1, Table 2). As cells of the CM3260 background are mutated in the GCN4 gene, we tested whether the expression of GCN4 interfered with siderophore transport. We found that overexpression of GCN4 on a multicopy plasmid in CM3260 and CM32604sit1 cells did not significantly change the rate of iron uptake from FOB, FC, FCH or TAF (data not shown).

As previously shown for FOB and FC (Lesuisse et al., 1998), there was competition between FOB and FCH, and between FCH and FC, in the DEY1433 strain (data not shown). TAF did not inhibit the uptake of FOB, FC or FCH (data not shown). Our kinetic parameters for the uptake of TAF and FCH were very similar to those published by Yun et al. (2000b) (data not shown).

\section{Differences in the regulation of siderophore transport and reductive iron uptake}

In a previous study (Lesuisse et al., 1998), we presented evidence that the transport of siderophore is regulated in an Aft1p-independent manner. Our conclusion arose from analysis of a mutant strain obtained by EMS mutagenesis. This strain was identified as an aft 1 mutant by complementation with AFT1 on a centromeric plasmid (data not shown). However, a recent study (Yun et al., 2000b) showed unambiguously that our conclusion was wrong: the SIT1 gene and homologues are actually regulated by Aft $1 \mathrm{p}$. We are currently trying to understand how a point mutation in AFT1 could lead to inactivation of the reductive pathway of iron uptake 
Table 4. Rates of iron uptake from ferric citrate or FOB by S. cerevisiae cells precultured and cultured under various conditions

Cells of the strain CM3260 were cultured overnight in a minimum medium (without iron or copper) supplemented with $1 \mu \mathrm{M}$ copper (' $-\mathrm{Fe}$ '), or $1 \mu \mathrm{M}$ copper plus $5 \mu \mathrm{M}$ ferric citrate (' $+\mathrm{Fe}$ '). Cells were then washed three times with distilled water, diluted 10-fold in the same medium with or without iron [as $5 \mu \mathrm{M}$ ferric citrate ( ${ }^{c}+\mathrm{Fe}^{a}$ ') or $5 \mu \mathrm{M} \mathrm{FOB}\left({ }^{c}+\mathrm{Fe}^{b}\right.$ ')] and cultured for 6 h. Where indicated (' + BPS'), the culture medium contained $100 \mu \mathrm{M}$ BPS. Iron uptake by the cells was then measured as described in Methods with either $2 \mu \mathrm{M}$ ferric citrate or $2 \mu \mathrm{M}$ FOB. Representative data from one of three independent experiments are shown.

\begin{tabular}{|lllc|}
\hline $\begin{array}{l}\text { Preculture } \\
\text { conditions }\end{array}$ & \multicolumn{1}{c}{$\begin{array}{c}\text { Culture } \\
\text { conditions }\end{array}$} & \multicolumn{2}{c|}{$\begin{array}{c}\text { Iron uptake rate } \\
{\left[\text { pmol min }^{-1}\left(\mathrm{OD}_{600} \text { unit }\right)^{-1}\right]}\end{array}$} \\
\cline { 3 - 4 } & & $\begin{array}{c}\text { Reductive uptake } \\
\text { of } \mathrm{Fe}(\mathrm{III}) \text { citrate }\end{array}$ & $\begin{array}{c}\text { Non-reductive } \\
\text { uptake of FOB }\end{array}$ \\
\hline$+\mathrm{Fe}$ & $+\mathrm{Fe}^{a}$ & $0 \cdot 5$ & $0 \cdot 2$ \\
$+\mathrm{Fe}$ & $+\mathrm{Fe}$ & $0 \cdot 5$ & $0 \cdot 8$ \\
$+\mathrm{Fe}$ & $-\mathrm{Fe}$ & $1 \cdot 2$ & $1 \cdot 5$ \\
$+\mathrm{Fe}$ & $-\mathrm{Fe}+\mathrm{BPS}$ & $6 \cdot 8$ & $3 \cdot 0$ \\
$-\mathrm{Fe}$ & $+\mathrm{Fe}$ & $2 \cdot 7$ & $0 \cdot 3$ \\
$-\mathrm{Fe}$ & $+\mathrm{Fe}$ & $3 \cdot 5$ & $2 \cdot 5$ \\
$-\mathrm{Fe}$ & $-\mathrm{Fe}$ & $4 \cdot 5$ & $5 \cdot 0$ \\
$-\mathrm{Fe}$ & $-\mathrm{Fe}+\mathrm{BPS}$ & $2 \cdot 1$ & $6 \cdot 2$ \\
\hline
\end{tabular}

without affecting the non-reductive uptake of siderophores. The specific aspects of Aft regulation of siderophore transport will be discussed in another paper (P.-L. Blaiseau, E. Lesuisse \& J.-M. Camadro, unpublished). We confirm here that deletion of AFT1 completely abolished the transport of FOB, FC, FCH and TAF by the cells (data not shown). But the reductive and non-reductive pathways of iron uptake in $S$. cerevisiae were not regulated identically. First, full induction of both siderophore uptake and ferrous iron uptake did not occur under the same growth conditions. We previously reported (Lesuisse et al., 1998) that the induction of ferrous transport under iron deprivation was much higher than the induction of siderophore transport under the same conditions of growth in an iron-deficient medium. This was true when cells that had been cultured in a complete medium were washed and transferred to an iron-deficient medium for $6 \mathrm{~h}$ before measuring iron uptake from $\mathrm{Fe}^{2+}$ or FOB. The cell ferrireductase activity was then maximum and the rate of ferrous iron uptake was 10- to 30-fold higher than in cells grown in an iron-rich medium. Under the same conditions, the rate of FOB uptake was only increased fivefold (Lesuisse et al., 1998). However, when cells were cultured in iron-deficient medium only, there was a much greater increase in siderophore uptake. Thus, the induction of non-reductive uptake of siderophore seems to require more stringent conditions than reductive uptake (Table 4); the assumption that siderophore uptake is non-reductive is justified by our use of low $(1 \mu \mathrm{M})$ siderophore concentrations (see Introduction). Table 4 shows that a long period of iron deprivation (culture and preculture) was needed for the full induction of FOB transport, while reductive uptake of ferric citrate was maximum after only $6 \mathrm{~h}$ of iron deprivation. We previously observed that cell ferrireductase activity seemed to depend more on the flux of iron entering the cells in exponential-growth phase than on the absolute iron content of the cells (Lesuisse \& Labbe, 1989). This could account for the high rate of reductive iron uptake by iron-replete cells subjected to iron-deprivation for short periods. Table 4 also shows that iron in the growth medium was more efficient at repressing reductive and non-reductive iron uptake when presented as ferric citrate than as FOB. This suggests that the intracellular processing of the two forms of iron is different.

The Ssn6-Tup1 repressor forms one of the largest and most important gene-regulatory circuits in yeast. In previous unpublished experiments, we observed an effect of TUP1 deletion on cell ferrireductase activity. We checked if TUP1/SSN6 expression could influence reductive and/or non-reductive uptake of iron. The relative dependence of the two pathways on these transcription factors indicated differences in the regulation of reductive and non-reductive iron uptake pathways in S. cerevisiae. The reductive uptake of ferric citrate was decreased in strains with disrupted TUP1 or SSN6 genes (Fig. 2). The opposite was true for the nonreductive uptake of siderophores, especially for that of the FCH-type siderophores (Fig. 2). The reductive uptake of ferric citrate by $\Delta t u p 1$ or $\Delta s s n 6$ strains was decreased under iron-sufficient conditions and unchanged by iron deprivation (compared to the wild-type grown under iron-sufficient conditions). Under the same conditions, the non-reductive uptake of FC and $\mathrm{FCH}$ was constitutively activated (Fig. 2). TAF uptake did not 


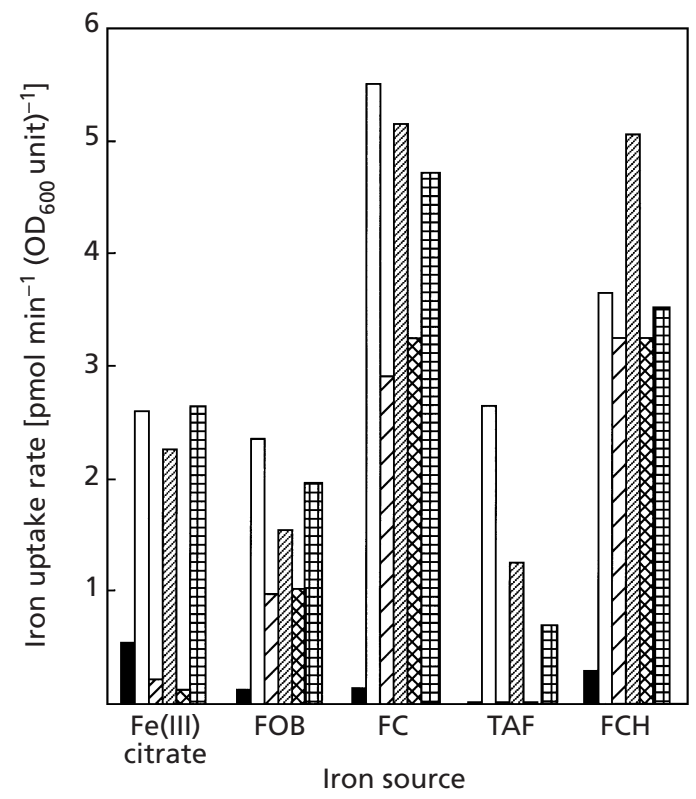

Fig. 2. Effect of disrupting TUP1 and SSN6 genes on reductive uptake of ferric citrate and non-reductive uptake of siderophores in S. cerevisiae. Wild-type, $\Delta$ tup 1 and $\Delta s s n 6$ cells were cultured overnight in iron-deficient medium ('-Fe'; without iron but with $1 \mu \mathrm{M}$ copper), or in iron-rich medium (' + Fe', same medium plus $10 \mu \mathrm{M}$ ferric citrate). In the morning, cells were diluted 10 -fold in the same medium and cultured for $6 \mathrm{~h}$ before iron uptake $(1 \mu \mathrm{M})$ was measured as described in Methods. $\square$, Wild-type $+\mathrm{Fe} ; \square$, wild-type $-\mathrm{Fe} ; \square, \Delta$ tup $1+\mathrm{Fe} ; \square$, $\Delta$ tup $1-\mathrm{Fe} ; \otimes, \Delta s s n 6+\mathrm{Fe}$; 团, $\Delta s s n 6-\mathrm{Fe}$. Representative data from one of six independent experiments are shown.

respond the same way as FC/FCH uptake to TUP1/ SSN6 disruption. The uptake of TAF was completely repressed in $\Delta t u p 1$ or $\Delta s s n 6$ mutant cells grown in ironrich medium, and was significantly decreased (compared to the wild-type) in the same mutants grown in irondeficient medium (Fig. 2).

It has been suggested that members of the Sit family function as $\mathrm{H}^{+} /$drug antiports (Goffeau et al., 1997). We therefore compared the effect of extracellular $\mathrm{pH}$ on the non-reductive uptake of siderophores (FCH and $\mathrm{FC}$ ) and the reductive uptake of ferric citrate (Fig. 3). The effect of $\mathrm{pH}$ on reductive and non-reductive uptakes was different. Reductive uptake was much more efficient at low $\mathrm{pH}$, while non-reductive uptake was maximal at pH 6-7 (Fig. 3). This result is not conclusive, but it is compatible with the hypothesis that Sit family proteins act as siderophore ${ }_{\text {in }} / \mathrm{H}_{\text {out }}^{+}$antiports.

\section{Intracellular fate of iron}

The gain-of-function $A F T 1^{\text {up }}$ mutation causes cells to be constitutively activated for the reductive transport of iron (Yamaguchi-Iwai et al., 1995). It had the same effect on the non-reductive uptake of FC, FCH, FOB and TAF (data not shown). AFT1 $1^{\text {up }}$ mutants seemed to accumulate siderophores inside the cells as the undissociated

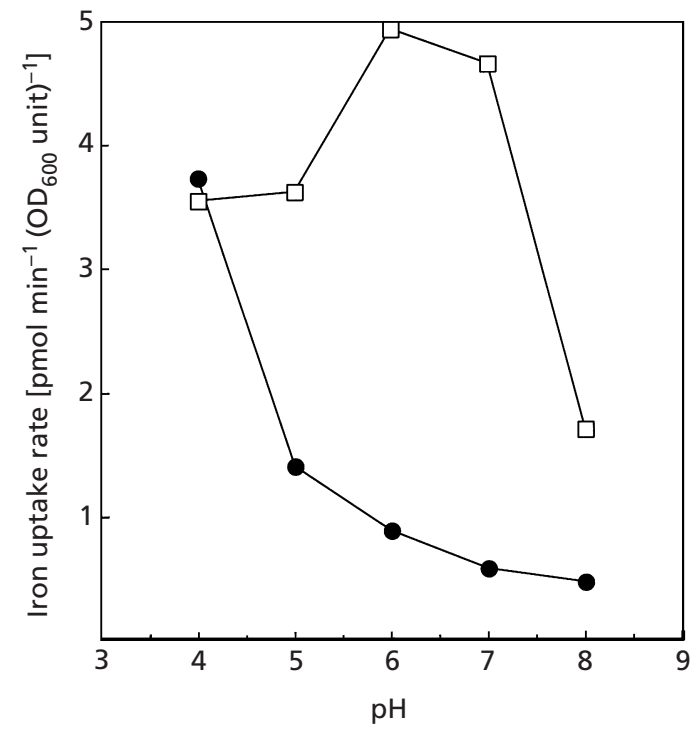

Fig. 3. Effect of $\mathrm{pH}$ on the reductive uptake rate of ferric citrate and on the non-reductive uptake rate of FC in $S$. cerevisiae. Cells of the strain CM3260 were cultured overnight in iron-deficient medium (without iron but with $1 \mu \mathrm{M}$ copper), diluted 10 -fold in the same medium $+100 \mu \mathrm{M}$ BPS and cultured for $6 \mathrm{~h}$. Iron uptake was measured as described in Methods with either $2 \mu \mathrm{M}$ ferric citrate (๑) or $2 \mu \mathrm{M} \mathrm{FCH}(\square)$ at various pHs (buffered by MES/MOPS, each $0.1 \mathrm{M}$ ). Representative data from one of three independent experiments are shown.

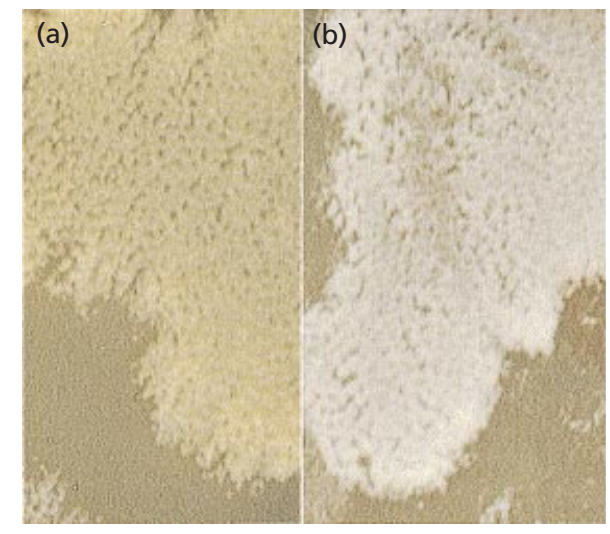

Fig. 4. Accumulation of $F O B$ inside $A F T 1^{\text {up }}$ mutant cells of $S$. cerevisiae. $A F T 1^{\text {up }}$ (a) and wild-type (b) cells were plated on minimum agar medium containing $10 \mu \mathrm{M}$ FOB and grown for $3 \mathrm{~d}$ at $30^{\circ} \mathrm{C}$.

ferric complex (Fig. 4). AFT1 $1^{\text {up }}$ cells grown on a FOBcontaining plate had the colour of the siderophore itself. The same observation was previously made with haemless mutants (Lesuisse \& Labbe, 1989). There are two possible explanations for these observations. One is that the siderophore itself acts as an iron-storage form, as shown for the fungus Neurospora crassa (Matzanke et al., 1987). The cells would then accumulate large amounts of the ferric siderophore as a direct conse- 


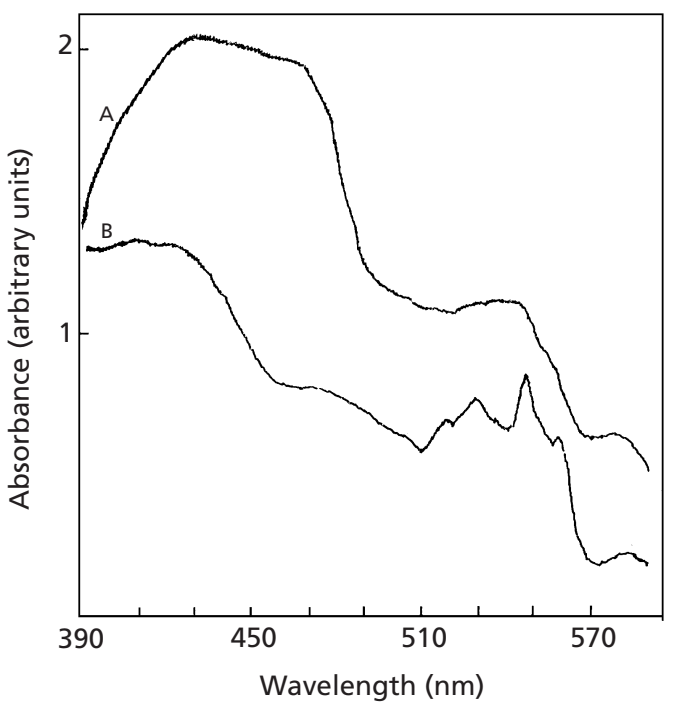

Fig. 5. Low-temperature spectra of $S$. cerevisiae cells loaded with $\mathrm{FOB}$ and induced $(A)$ or repressed (B) for the expression of the $A F T 1^{\text {up }}$ gene. $\Delta a f t 1$ cells were transformed with a multicopy plasmid bearing the $A F T 1^{\text {up }}$ ORF under the GAL4 promoter. Cells were grown for $24 \mathrm{~h}$ in a YNB-galactose medium containing $100 \mu \mathrm{M}$ FOB, washed with distilled water and transferred to an iron-deficient medium (without iron and copper) with either galactose or glucose as the carbon source and grown for $24 \mathrm{~h}$. Cells were then washed and lowtemperature spectra were recorded.

quence of the deregulation of transport. The other is that $A F T 1^{\text {up }}$ cells are defective at some step in the intracellular decomplexation of siderophores. A haem component could be involved in this dissociation step, which would explain why the same result was obtained with haem-less mutants (Lesuisse \& Labbe, 1989). We transformed a $\Delta a f t 1$ strain with a plasmid bearing the $A F T 1^{\text {up }}$ ORF under the inducible promoter of GAL4. The cells were grown on a galactose medium containing a large excess of FOB $(100 \mu \mathrm{M})$, harvested, washed with water and placed in an iron-deficient medium with galactose or glucose as the carbon source for $24 \mathrm{~h}$. We then recorded the low-temperature spectra of the washed cells (Fig. 5). Cells placed in the glucose medium (AFT1 ${ }^{\text {up }}$ expression repressed) showed a spectrum similar to that of the wild-type, indicating that most of the intracellular FOB was dissociated. In contrast, cells placed in galactose medium still showed a high absorbance peak in the range $420-440 \mathrm{~nm}$, indicating that the FOB remained undissociated inside the cells (Fig. 5). The total iron content of the cells were identical (not shown). This suggests that Aft1p is involved in the intracellular decomplexation of siderophores. Another observation supports the hypothesis that ferric siderophores are normally not accumulated inside the cells: in cells deleted for the YFH1 gene, reductive iron uptake is constitutively increased, iron accumulates into the mitochondria and is toxic (Babcock et al., 1997). The non-reductive uptake of FOB or FCH (but interestingly not of TAF) is also constitutively increased in $\Delta y f h 1$

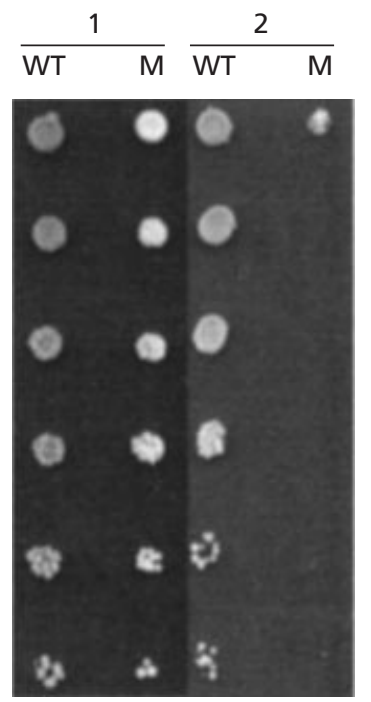

Fig. 6. Relative toxicity of ferric citrate and of $\mathrm{FCH}$ for a $\Delta y$ fh1 mutant of S. cerevisiae. Wild-type (WT) and $\Delta y f h 1$ mutant (M) cells were sequentially fivefold-diluted and then plated on YNB-glucose agar medium containing either $5 \mu \mathrm{M}$ ferric citrate (1) or $5 \mu \mathrm{M} \mathrm{FCH}(2)$.

mutants (data not shown). If $\mathrm{FOB} / \mathrm{FCH}$ were mainly accumulated inside the cells as the undissociated form, one would expect these siderophores to be less toxic than ferric citrate. But the opposite was true (Fig. 6), which could be due to the fact that the uptake rate for $\mathrm{FCH}$ was higher than that for ferric citrate. We used this property to select new mutants whose siderophore uptake/accumulation was affected. Aft $1 \mathrm{p}$ is known as a transcriptional activator, not as a repressor (Yamaguchi-Iwai et al., 1995). Thus, we needed to know how overexpression of $A F T 1^{\text {up }}$ could lead to a defect in siderophore use by the cells. One explanation is that Aft1p activates a gene whose product is involved in the intracellular storage of siderophores in a compartment where decomplexation of the molecule cannot occur. We investigated the intracellular storage of siderophores using fluorescent derivatives of $\mathrm{FCH}$, as previously described for Ustilago maydis (Ardon et al., 1998). Wildtype cells took up very little of the fluorescent probes, so that we could not see any signal by confocal fluorescence microscopy (data not shown). But an $A F T 1^{\text {up }}$ strain took up fluorescent material, which was seen in peri-vacuolar structures (Fig. 7). Fractionation on a Ficoll gradient showed that most of the ${ }^{55} \mathrm{Fe}$-labelled FOB taken up into $A F T 1^{\text {up }}$ cells was in the same fraction as the late endosome marker Pep12 (Fig. 8). Unexpectedly, much less iron was associated with the vacuolar fraction, while a significant peak of iron co-migrated with the mitochondrial fraction (Fig. 8). Yun et al. (2000a) recently showed that Sit1p was mostly associated with an internal compartment (probably late endosome), unlike the Fet3p-Ftr1p complex (components of the reductive uptake system), which was mostly associated with the plasma membrane fraction. Therefore, we tested the possibility that the uptake of siderophore 
(a)

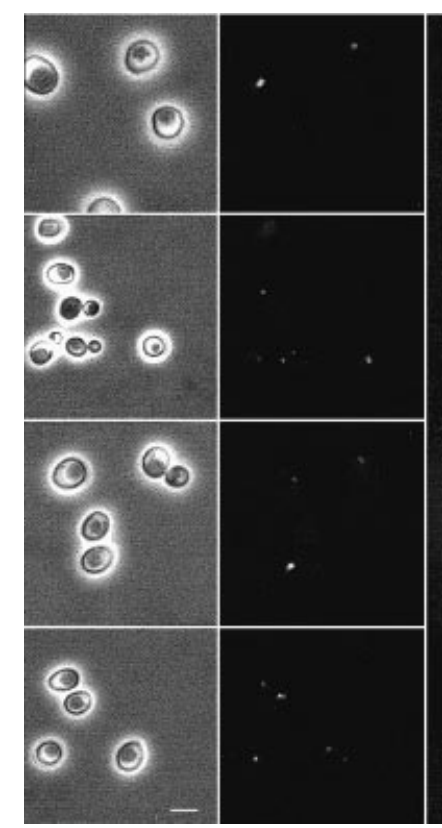

(c)

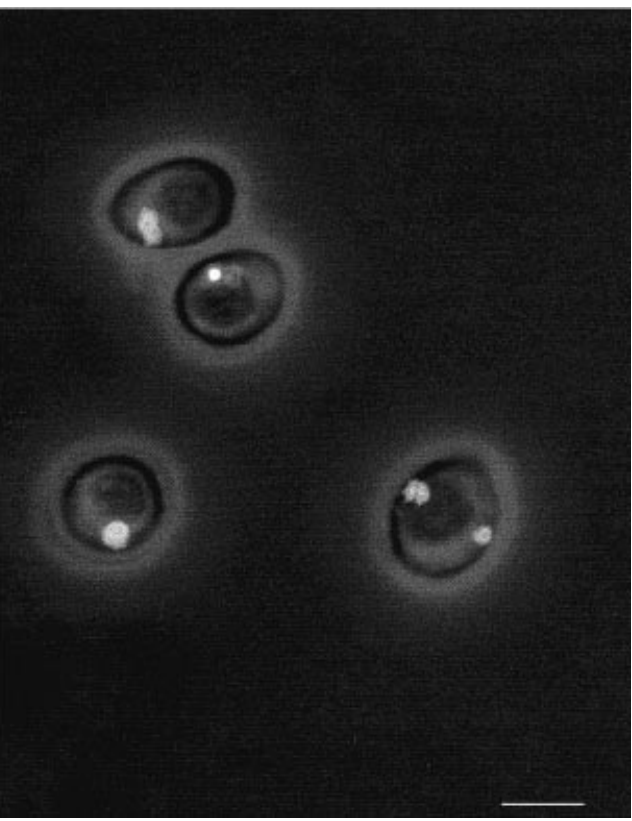

Fig. 7. Confocal micrographs of $S$. cerevisiae M2p. Cells were grown for $24 \mathrm{~h}$ with $10 \mu \mathrm{M}$ of a B9 fluorescent analogue of FCH (Ardon et al., 1998). Fluorescence is concentrated in vesicles within the cells. Superimposition of the pictures recorded by phase-contrast microscopy (a) and by confocal fluorescence microscopy (b) shows that the fluorescent material lies around the vacuole (c). Bars, $5 \mu \mathrm{m}$ (bar in a also applies to b).

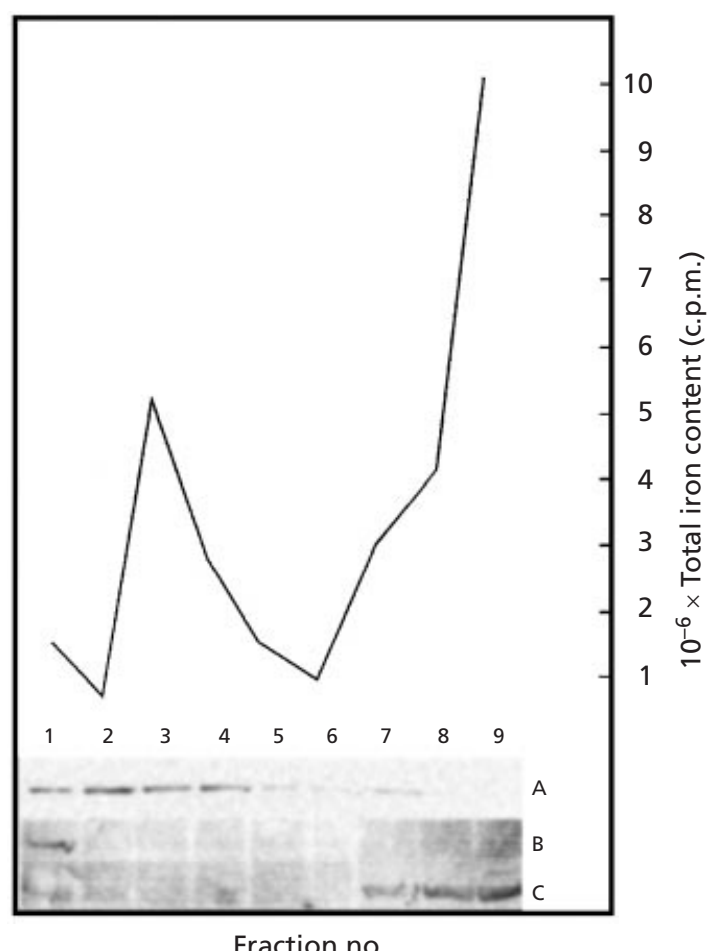

Fraction no. depended on endocytosis. We tested the capacity of a thermosensitive act1 strain, unable to carry out endocytosis at $37^{\circ} \mathrm{C}$ (Kubler \& Riezman, 1993), to reductively take up iron from ferric citrate, or nonreductively from FOB (each $1 \mu \mathrm{M}$ ), after growing in various media (complete medium, minimum iron-deficient medium, minimum iron-rich medium) and incubation at 28 or $37^{\circ} \mathrm{C}$ in the presence of ${ }^{55} \mathrm{Fe}$. The reductive uptake of ferric citrate by the act 1 strain was somewhat lower than that of the wild-type, but its nonreductive uptake of FOB seemed to be unaffected. Data from a typical experiment were as follows: cells of the wild-type strain and of the act 1 mutant were cultured for $6 \mathrm{~h}$ at $28^{\circ} \mathrm{C}$ in iron-deficient medium and than shifted to $37^{\circ} \mathrm{C}$ for $30 \mathrm{~min}$ before iron uptake was measured $\left(\right.$ at $\left.37^{\circ} \mathrm{C}\right)$. The uptake rate of ferric citrate was $9 \cdot 4 \pm 1 \cdot 1 \mathrm{pmol} \mathrm{min}^{-1}\left(\mathrm{OD}_{600} \text { unit }\right)^{-1}$ for the wildtype and $6.9 \pm 0.8 \mathrm{pmol} \mathrm{min}^{-1}\left(\mathrm{OD}_{600}\right.$ unit $^{-1}$ for the act 1 mutant. These values were, respectively, $2 \cdot 0 \pm 0 \cdot 15$ and $2 \cdot 8 \pm 0 \cdot 2 \mathrm{pmol} \mathrm{min}^{-1}\left(\mathrm{OD}_{600} \text { unit }\right)^{-1}$ for the uptake of FOB (mean \pm sE from three experiments). The transport of TAF, FC and FCH was similarly unaffected in the act 1 mutant at the non-permissive temperature (data not shown). We conclude that siderophore uptake does not require Act1-mediated endocytosis.

\section{DISCUSSION}

S. cerevisiae has proven a very good model for studying reductive iron uptake in eukaryotes (reviewed by Askwith \& Kaplan, 1998) and it will probably help us to better understand non-reductive iron uptake as well, even though it does not itself produce any siderophores. We previously showed that disruption of SIT1 blocked FOB uptake by S. cerevisiae (strain DEY1433) without
Fig. 8. Intracellular distribution of iron in an $A F T 1^{\text {up }}$ strain of $S$. cerevisiae loaded with ${ }^{55} \mathrm{Fe}$-labelled FOB. Cells of the strain M2p were grown overnight in YNB-raffinose medium containing $100 \mu \mathrm{M}$ FOB, lysed and the cell lysate separated on a discontinuous Ficoll gradient. The total amount of iron in each fraction (numbered 1 to 8 from top to bottom) was measured. Samples of the same fractions were used for Western blotting experiments, in which markers of mitochondria (ferrochelatase, A), of the vacuole (vacuolar ATPase, B) and of the late endosome (pep12p, C) were revealed by specific antibodies. 
affecting the transport of FC (Lesuisse et al., 1998). However, there is competition for the transport of the two siderophores. This suggested that the uptake of a given siderophore is very specific and that some step common to several siderophores are upstream or downstream of the transport system itself (Lesuisse et al., 1998). Here again, we found that there is competition between FOB, FC and FCH. Like Yun et al. (2000b), we found that siderophore transport by $S$. cerevisiae is not strictly specific. While FOB and TAF are each taken up via a single transporter (Sit1p and Taf1, respectively), several transporters (especially Sit1p and Arn1p) contribute to the uptake of FCH and FC. The apparent specificity is also strongly strain-dependent. Thus, it is not clear whether or not a single protein is responsible for both recognition and transport of siderophores by $S$. cerevisiae. We are examining this question with in vitro binding experiments on isolated plasma membranes. The fact that the uptake of several siderophores (FOB, $\mathrm{FC}, \mathrm{FCH}$ ) is competitive implies that other proteins are involved in their transport. We are currently trying to identify these proteins by analysing new mutant strains affected in siderophore uptake/use. The present study suggests that the siderophore FOB is associated with an endosomal compartment when it accumulates inside the cells. Another study (Yun et al., 2000a) showed that Sit1p is also associated with the late endosome compartment. We used $A F T 1^{\text {up }}$ mutant cells, which accumulate large amounts of siderophores. The intracellular processing of siderophores is probably blocked in $A F T 1^{\text {up }}$ cells. This would explain why iron was released from FOB within the cells when the $A F T 1^{\text {up }}$ gene on a plasmid was turned off in a $\Delta a f t 1$ strain loaded with FOB. Yun et al. (2000a) proposed that Sit1p is involved downstream of the uptake system for FOB, which itself could involve endocytosis. However, this possibility can be ruled out since a mutant completely blocked for endocytosis showed no defect in siderophore uptake. In addition, involvement of Sit1p downstream of the uptake system would not explain why disruption of SIT1 completely abolished FOB uptake in some strains. Sit $1 \mathrm{p}$ is more likely to act as a transporter at the cell surface and be rapidly recycled by internalization. Nothing is known about the intracellular processing of siderophores in S. cerevisae. Preliminary studies suggest that a haemoprotein is involved in the reductive decomplexation of siderophores inside the cells (Lesuisse \& Labbe, 1989). This could involve one of the Fre1p/ Fre2p homologues. Many other aspects of siderophore metabolism in $S$. cerevisiae remain to be clarified, including the energetics of transport, the relationship between recognition and transport, and its regulation. These questions are under investigation in our laboratory.

\section{ACKNOWLEDGEMENTS}

We thank Dr G. Winkelmann for kindly donating ferricrocin, Dr A. Shanzer for providing the fluorescent ferrichrome analogues and Dr H. Haas for donating triacetylfusarinine C. This work was supported by grants from CNRS and Ministère de la Recherche et de l'Enseignement Supérieur (Programme de Recherches Fondamentales en Microbiologie et Maladies Infectieuses). We thank G. Géraud for his help in confocal microscopy studies and Dr O. Parkes for checking the English text.

\section{REFERENCES}

Ardon, O., Nudelman, R., Caris, C., Libman, J., Shanzer, A., Chen, Y. \& Hadar, Y. (1998). Iron uptake in Ustilago maydis: tracking the iron path. J Bacteriol 180, 2021-2026.

Askwith, C. \& Kaplan, J. (1998). Iron and copper transport in yeast and its relevance to human disease. Trends Biochem Sci 23, 135-138.

Askwith, C., Eide, D., Van Ho, A., Bernard, P. S., Li, L., DavisKaplan, S., Sipe, D. M. \& Kaplan, J. (1994). The FET3 gene of $S$. cerevisiae encodes a multicopper oxidase required for ferrous iron uptake. Cell 76, 403-410.

Babcock, M., de Silva, D., Oaks, R., Davis-Kaplan, S., Jiralerspong, S., Montermini, L., Pandolfo, M. \& Kaplan, J. (1997). Regulation of mitochondrial iron accumulation by Yfh1p, a putative homolog of frataxin. Science 276, 1709-1712.

Berner, I., Yakirevitch, P., Libman, J., Shanzer, A. \& Winkelmann, G. (1991). Chiral linear hydroxamates as biomimetic analogues of ferrioxamine and coprogen and their use in probing siderophorereceptor specificity in bacteria and fungi. Biol Met 4, 186-191.

Burns, N., Grimwade, B., Ross-Macdonald, P. B., Choi, E. Y., Finberg, K., Roeder, G. S. \& Snyder, M. (1994). Large-scale analysis of gene expression, protein localization, and gene disruption in Saccharomyces cerevisiae. Genes Dev 8, 1087-1105.

Camadro, J.-M. \& Labbe, P. (1988). Purification and properties of ferrochelatase from the yeast Saccharomyces cerevisiae. J Biol Chem 263, 11675-11682.

Dancis, A., Klausner, R. D., Hinnebusch, A. G. \& Barriocanal, J. G. (1990). Genetic evidence that ferric reductase is required for iron uptake in Saccharomyces cerevisiae. Mol Cell Biol 10, 2294-2301.

Dancis, A., Roman, D. G., Anderson, G. J., Hinnebusch, A. G. \& Klausner, R. D. (1992). Ferric reductase of Saccharomyces cerevisiae: molecular characterization, role in iron uptake, and transcriptional control by iron. Proc Natl Acad Sci U S A 89, 3869-3873.

Dix, D. R., Bridgham, J. T., Broderius, M. A., Byersdorfer, C. A. \& Eide, D. J. (1994). The FET4 gene encodes the low affinity Fe(II) transport protein of Saccharomyces cerevisiae. J Biol Chem 269, 26092-26099.

Ecker, D. J. \& Emery, T. (1983). Iron uptake from ferrichrome A and iron citrate in Ustilago sphaerogena. J Bacteriol 155, 616-622.

Emery, T. (1986). Exchange of iron by gallium in siderophores. Biochemistry 25, 4629-4633.

Georgatsou, E. \& Alexandraki, D. (1994). Two distinctly regulated genes are required for ferric reduction, the first step of iron uptake in Saccharomyces cerevisiae. Mol Cell Biol 14, 3065-3073.

Goffeau, A., Park, J., Paulsen, I. T., Jonniaux, J. L., Dinh, T., Mordant, P. \& Saier, M. H., Jr (1997). Multidrug-resistant transport proteins in yeast: complete inventory and phylogenetic characterization of yeast open reading frames with the major facilitator superfamily. Yeast 13, 43-54.

Heymann, P., Ernst, J. F. \& Winkelmann, G. (1999). Identification of a fungal triacetylfusarinine $C$ siderophore transport gene (TAF1) in Saccharomyces cerevisiae as a member of the major facilitator superfamily. Biometals 12, 301-306.

Heymann, P., Ernst, J. F. \& Winkelmann, G. (2000a). A gene of the 
major facilitator superfamily encodes a transporter for enterobactin (Enb1p) in Saccharomyces cerevisiae. Biometals 13, 65-72.

Heymann, P., Ernst, J. F. \& Winkelmann, G. (2000b). Identification and substrate specificity of a ferrichrome-type siderophore transporter (Arn1p) in Saccharomyces cerevisiae. FEMS Microbiol Lett 15, 221-227.

Kubler, E. \& Riezman, H. (1993). Actin and fimbrin are required for the internalization step of endocytosis in yeast. EMBO J 12, 2855-2862.

Lesuisse, E. \& Labbe, P. (1989). Reductive and non-reductive mechanisms of iron assimilation in the yeast Saccharomyces cerevisiae. J Gen Microbiol 135, 257-263.

Lesuisse, E., Raguzzi, F. \& Crichton, R. R. (1987). Iron uptake by the yeast Saccharomyces cerevisiae: involvement of a reduction step. J Gen Microbiol 133, 3229-3236.

Lesuisse, E., Simon-Casteras, M. \& Labbe, P. (1998). Siderophoremediated iron uptake in Saccharomyces cerevisiae: the SIT1 gene encodes a ferrioxamine B permease that belongs to the major facilitator superfamily. Microbiology 144, 3455-3462.

Matzanke, B. F., Bill, E., Trautwein, A. X. \& Winkelmann, G. (1987). Role of siderophores in iron storage in spores of Neurospora crassa and Aspergillus ochraceus. J Bacteriol 169, 5873-5876.
Raguzzi, F., Lesuisse, E. \& Crichton, R. (1988). Iron storage in Saccharomyces cerevisiae. FEBS Lett 231, 253-258.

Stearman, R., Yuan, D. S., Yamaguchi-Iwai, Y., Klausner, R. D. \& Dancis, A. (1996). A permease-oxidase complex involved in highaffinity iron uptake in yeast. Science 271, 1552-1557.

Wiebe, C. \& Winkelmann, G. (1975). Kinetic studies on the specificity of chelate-iron uptake in Aspergillus. J Bacteriol 123, 837-842.

Yamaguchi-Iwai, Y., Dancis, A. \& Klausner, R. D. (1995). AFT1: a mediator of iron regulated transcriptional control in Saccharomyces cerevisiae. EMBO J 14, 1231-1239.

Yun, C. W., Ferea, T., Rashford, J., Ardon, O., Brown, P. O., Botstein, D., Kaplan, J. \& Philpott, C. C. (2000a). Desferrioxaminemediated iron uptake in Saccharomyces cerevisiae. Evidence for two pathways of iron uptake. J Biol Chem 275, 10709-10715.

Yun, C. W., Tiedeman, J. S., Moore, R. E. \& Philpott, C. C. (2000b). Siderophore-iron uptake in Saccharomyces cerevisiae. Identification of ferrichrome and fusarinine transporters. J Biol Chem 275, 16354-16359.

Received 18 July 2000; revised 26 October 2000; accepted 3 November 2000. 